\title{
BMJ Open UK research spend in 2008 and 2012: comparing stroke, cancer, coronary heart disease and dementia
}

\author{
Ramon Luengo-Fernandez, Jose Leal, Alastair Gray
}

To cite: Luengo-Fernandez $\mathrm{R}$, Leal J, Gray A. UK research spend in 2008 and 2012: comparing stroke, cancer, coronary heart disease and dementia. BMJ Open 2015;5: e006648. doi:10.1136/ bmjopen-2014-006648

- Prepublication history and additional material is available. To view please visit the journal (http://dx.doi.org/ 10.1136/bmjopen-2014006648)

Received 16 September 2014 Revised 29 January 2015 Accepted 6 February 2015

CrossMark

Health Economics Research Centre, Nuffield Department of Population Health, Old Road Campus, University of Oxford, Oxford, UK

Correspondence to Dr Ramon LuengoFernandez; ramon.luengo-fernandez@ dph.ox.ac.uk

\section{ABSTRACT}

Objective: To assess UK governmental and charity research funding in 2012 for cancer, coronary heart disease (CHD), dementia and stroke, and to make comparisons with 2008 levels.

Design: Analysis of research expenditure.

Setting: United Kingdom.

Main outcome measures: We identified UK governmental agencies and charities providing health research funding to determine the 2012 levels of funding for cancer, CHD, dementia and stroke. Levels of research funding were compared to burden of disease measures, including prevalence, disability adjusted life years and economic burden.

Results: The combined research funding into cancer, $\mathrm{CHD}$, dementia and stroke by governmental and charity organisations in 2012 was $£ 856$ million, of which $£ 544$ million (64\%) was devoted to cancer, £166 million (19\%) to CHD, £90 million (11\%) to dementia and £56 million $(7 \%)$ to stroke. For every $£ 10$ of health and social care costs attributable to each disease, cancer received $£ 1.08$ in research funding, $\mathrm{CHD} £ 0.65$, stroke $£ 0.19$ and dementia $£ 0.08$. A considerable shift in the distribution of government research funding was observed between 2008 and 2012. In 2008, 66\% of governmental research funding into the four conditions under study was devoted to cancer, $21 \%$ to $\mathrm{CHD}, 9 \%$ to dementia and $4 \%$ to stroke. In 2012 , the proportions devoted to dementia and stroke had increased to $21 \%$ and $12 \%$, respectively, with cancer accounting for $45 \%$ of total research spend.

Conclusions: Although there has been much progress by government to increase levels of research funding for dementia and stroke, these areas remain underfunded when compared with the burden of disease.

\section{INTRODUCTION}

Cancer, coronary heart disease (CHD), dementia and stroke are leading causes of death and disability. ${ }^{1}$ In the UK, these four diseases accounted for $55 \%$ of all deaths in 2012 and for 5.5 million disability adjusted life years (DALYs). ${ }^{2-4}$ Their impact on the health and social care services is also

\section{Strengths and limitations of this study}

A UK government review recommended that the impact of diseases on the population and economy should be assessed to inform health research priorities.

- Since 2010, there have been significant changes in medical research allocation policies, particularly by the UK central government.

- There has been a considerable shift in the way government distributes research funding between 2008 and 2012. Out of the combined government research funding for cancer, coronary heart disease, dementia and stroke, $33 \%$ was devoted to dementia and stroke in 2012, compared with just $13 \%$ in 2008 .

- As a result of the very large numbers of registered UK charities, we were unable to extract funding information from all of them.

- We omitted industry research and development on the grounds that it is not directly a subject of public policy.

considerable, with a combined cost of £20 billion in 2008. Owing to the burden placed on patients, carers and the healthcare system, there is an argument for investing in research so as to better understand how to prevent, diagnose, treat and manage these diseases.

In 2006, a UK governmental review recommended that the impact of diseases on the population should be assessed to help determine society's health priorities and in turn, inform research priorities. ${ }^{5}$ In contrast, research has highlighted that most of the UK medical research funding on chronic disease is allocated to cancer with other high burden conditions, such as dementia or stroke, receiving relatively low levels of research funding. ${ }^{6-9}$ However, over recent years, there have been significant policy changes affecting the way medical research is allocated, particularly by the UK central government. In 2010, the UK programme for government highlighted that it "... will prioritise dementia 
research within the health research and development budget." ${ }^{10}$ It is, therefore, important to assess whether research expenditure has moved more into line with the impact of different diseases on society. This is particularly relevant in the case of governmental-funded research, where limited funds have to be allocated over a large number of different diseases.

One approach is to quantify research expenditure and then compare it against measures of disease burden, the rationale being that research funding should be allocated towards diseases with the highest burden. The aim of this study is to estimate UK governmental and charity research funding in 2012 for cancer, CHD, dementia and stroke, to compare these quantums against different measures of disease burden and to assess whether there have been significant changes in the relative levels of research funding for these four conditions between 2008 and 2012.

\section{METHODS}

\section{Research funding}

In the UK, research into health and medical sciences is funded by a number of different organisations, including the Department of Health and its counterparts in the devolved administrations; the UK research councils; charities; and research and development (R\&D) investments from the pharmaceutical and biotechnology industries. ${ }^{5}$ In line with other studies evaluating the levels of UK health research funding, research funding provided by industry was excluded from this analysis. ${ }^{9} 11$

For the purposes of this study, we focused on governmental and charitable funding from UK-based organisations, covering all types of human research into stroke, cancer, dementia and CHD. Although awards to overseas institutions from these funders were included, international funding sources to UK institutions were excluded (ie, these were under no obligation to file their accounts and annual reports in the UK). Research expenditure on basic science activities or generic health research, which are difficult to attribute to a specific disease, were excluded.

We included all governmental organisations in the UK Clinical Research Collaboration. For each governmental organisation, we searched for data on the total number and the value of research grants and fellowships awarded, as well as any other research infrastructure expenditure in the year 2012. If total research expenditure (grants/fellowships and infrastructure) were not reported by disease of interest, we used a two-step approach. First, we allocated research grants and fellowships to the four conditions under study after reviewing their titles, project key words and scientific abstracts. Second, we used the distribution of research grants and fellowships by disease in each organisation to allocate the respective research infrastructure expenditure.

Charities funding health research were identified from two different sources. First, we obtained details of all the member charities of the Association of Medical Research Charities (AMRC). Second, we obtained a list of all the charities potentially funding health research from the Charity Commission for England and Wales. Given that over 15000 charities were identified, we only considered the first 214 charities ranked in terms of annual income, which represented $75 \%$ of the total income. We excluded educational/research organisations, such as universities or royal colleges which were registered as charities, as these receive a high proportion of their income from government and charitable grants. For each charity, we sought to determine if the charity funded health research and if so, the levels for the four conditions under study. Annual reports and accounts (derived either from the charity's website or the Charity Commission) were reviewed to obtain information on the research grants funded. If the information contained within the annual report was not detailed enough, the charity's website was browsed to identify all health research-funded grants.

For both charities and government, a researcher used the available information available for each grant (eg, title, summary, background, etc) to categorise all research spending on the four diseases under question. Grants were subsequently reviewed by the lead author (RL-F), with final classification being made by him in all cases. In the cases where a research grant covered two or more diseases of interest, research expenditure was apportioned to each of the relevant diseases.

Standard $\chi^{2}$ tests were used to assess whether the relative proportions of research funding into each of the conditions under study had significantly changed between 2008 and 2012. This analysis was repeated for government organisations and charities.

\section{Disease burden}

Levels of research funding from UK governmental organisations and charities for cancer, CHD, dementia and stroke were compared against different measures of disease burden.

\section{Disease prevalence in 2012}

Prevalence rates of diagnosed and undiagnosed dementia cases were obtained from the European Community Concerted Action on the Epidemiology and Prevention of Dementia (EURODEM) for individuals aged under 65 years, ${ }^{12}$ and from the Cognitive Function and Ageing Study for those aged 65 years and above. ${ }^{13}$ Prevalence rates of dementia were applied to UK population estimates for 2012. ${ }^{14}$ The prevalence of cancer in the UK (with or having survived cancer) was updated from 2008 estimates, assuming an annual $3 \%$ annual increase. ${ }^{15}$ The prevalence of stroke and CHD in the UK was obtained from Quality and Outcomes Framework data. ${ }^{16} 17$

\section{DALYs in 2012}

DALYs are a measure combining years of life lost due to premature mortality and years of life lost due to time 
lived in states of less than full health. The rate, per 100000 of population, of DALYs lost for cancer, dementia, stroke and CHD was obtained from Global Burden of Disease for the year $2010^{18}$ and applied to $2012 \mathrm{popu}-$ lation estimates. ${ }^{14}$

\section{Economic burden in 2012}

The economic burden of cancer, CHD, dementia and stroke was obtained from a previously published study that evaluated their cost to the UK health and social care system in 2008 using the same methodology. ${ }^{9}$ This study adopted a prevalence approach whereby all costs within the most recent years for which data were available were measured regardless of the date of disease onset and adopting a 'top down' approach, that is, using aggregate data. We used the Hospital and Community Health Services (HCHS) pay and price inflation index to update costs from 2008 to $2012 .^{19}$

All information for this study was collated and analysed in Microsoft Excel 2010.

\section{RESULTS}

\section{Study sample}

\section{Governmental organisations}

We obtained information on the total number of research grants and fellowships awarded in the year 2012 for all eight of the governmental organisations identified. A total of 1439 research grants and fellowships, with a total combined value of $£ 750$ million (see online supplementary table S1), and $£ 1138$ million of research infrastructure expenditure were considered (see online supplementary table S2).

\section{Charities}

At the time of this research, the AMRC consisted of 121 charities. Of these charities, $51(42 \%)$ were included in the analysis. AMRC listed charities were excluded if: (1) their health research funding was in diseases other than dementia, cancer, CHD or stroke $(n=65,93 \%)$; (2) it was not possible to elicit the nature of their research grants $(n=2)$; (3) they were registered outside the UK $(\mathrm{n}=1)$; (4) they were a Royal College $(\mathrm{n}=1)$ and (5) they had provided no new grants during the year $2012(\mathrm{n}=1)$.

A total of 15773 charities were identified through the Charity Commission as potentially funding medical research. Owing to the very high number of charities identified, we only included the first 214 representing $75 \%$ of the total combined income. Of these, only 15 (7\%) were included in the analysis. Reasons for excluding the remaining 199 charities were: (1) they provided no health research funding $(n=138)$; (2) they had already been identified through AMRC $(n=26)$; (3) they provided no research funding in the diseases of interest $(\mathrm{n}=21)$; (4) they were a Royal College $(\mathrm{n}=7)$; (5) they were a university/educational establishment $(n=6)$ and (6) it was not possible to elicit the nature of their research grants $(n=1)$.
Through the AMRC and Charity Commission we identified a total of 66 charities providing research funding into dementia, cancer, CHD and/or stroke. Of these 66 charities, 34 (52\%) were identified solely by the AMRC, $15(23 \%)$ solely by the Charity Commission, and 17 (26\%) by both the AMRC and Charity Commission. A list of all the charities included in the analysis is reported in online supplementary table S3, including the financial year to which the accounts pertain.

\section{Levels of research funding}

A total of 1439 research grants and fellowships from governmental organisations were reviewed. Of these, 97 related to cancer, 51 to $\mathrm{CHD}, 41$ to dementia and 27 to stroke (table 1). The total combined values of the 1439 research grants reviewed was $£ 750$ million, of which $£ 55$ million (7\%) was on cancer, £24 million (3\%) on CHD, $£ 22$ million (3\%) on dementia and £13 million (2\%) on stroke.

To the levels of research grant funding we added the respective research infrastructure expenditure by disease. In addition, we obtained data from the MRC on the combined grant and infrastructure research spend for the four conditions under study. For government, the combined total research spend on cancer, CHD, dementia and stroke was $£ 347$ million, of which $£ 157$ million (45\%) was devoted to cancer, $£ 75$ million (21\%) to CHD, £73 million (21\%) to dementia and $£ 43$ million (12\%) to stroke (table 2).

Of the 66 charities included in the analysis, 52 (79\%) funded research into cancer, $17(26 \%)$ funded CHD research, $12(18 \%)$ funded stroke research and 11 $(17 \%)$ funded research into dementia. Of these charities, $27(41 \%)$ were cancer-specific charities (ie, they only funded research into cancer). When combined, these charities spent $£ 509$ million on cancer, CHD, dementia and stroke research (table 1). Most of this research funding was devoted to cancer ( $£ 387$ million$76 \%$ ), followed by CHD (£91 million-18\%), dementia (£17 million-3\%) and stroke (£13 million-3\%).

In total, combined research funding into cancer, CHD, dementia and stroke by the charities and governmental organisations under study was $£ 856$ million. Of this total funding, £544 million (64\%) was devoted to cancer, £166 million (19\%) was devoted to CHD, £90 million $(11 \%)$ to dementia and $£ 56$ million (7\%) to stroke (table 2). Both in total and as a proportion of total research funding into the four diseases, governmental organisations devoted considerably more research funding into dementia and stroke than did the charities.

When compared with the levels of research funding in 2008, governmental organisations devoted considerably more research funding into dementia and stroke in $2012(\mathrm{p}=0.005)$. In 2008, governmental organisations devoted $£ 36$ million (9\% of the total spent on the four diseases) to dementia, compared with $£ 73$ million $(21 \%)$ in 2012 (table 2). Similar increases in stroke 
Table 1 Total research grant expenditure by governmental organisations

\begin{tabular}{lllll}
\hline & $\begin{array}{l}\text { Total research } \\
\text { grant expenditure, } £\end{array}$ & $\begin{array}{l}\text { Number of } \\
\text { research grants }\end{array}$ & $\begin{array}{l}\text { Mean (SD) research } \\
\text { grant expenditure, } £\end{array}$ & $\begin{array}{l}\text { Median (IQR) research } \\
\text { grant expenditure, } £\end{array}$ \\
\hline Cancer & 54702431 & 97 & $569943(640027)$ & $316544(217911-539780)$ \\
CHD & 24067609 & 51 & $471914(520496)$ & $288570(179496-526114)$ \\
Dementia & 21946131 & 41 & $535271(522269)$ & $367226(225934-546825)$ \\
Stroke & 13295401 & 27 & $474836(619431)$ & $248994(218327-403634)$ \\
\hline
\end{tabular}

$\mathrm{CHD}$, coronary heart disease.

research funding were observed, with levels of stroke research funding being $£ 18$ million (4\%) in 2007/2008 compared with $£ 43$ million (12\%) in 2012 . However, in contrast to government research funding, the relative proportions of charity research funding into cancer, CHD, dementia and stroke remained virtually unchanged between 2007/2008 and 2012 ( $p=0.770)$.

\section{Research funding and burden of disease}

In the UK, there were approximately 2.3 million cases of cancer, 2.3 million CHD cases, 0.8 million cases of dementia and 1.2 million stroke cases (table 3). Per person with disease, the total levels of research funding equated to $£ 241$ per person with cancer, £73 per person with CHD, $£ 118$ per person with dementia and $£ 48$ per person with stroke.

A total of 2.9 million DALYs were lost due to cancer, 1.5 million due to CHD, 0.4 million due to dementia and 0.7 million due to stroke (table 3). Per DALY lost, dementia received the highest levels of total research funding at $£ 225$ per DALY lost, followed by cancer (£187), CHD (£110) and stroke (£82).

Dementia was found to have the lowest healthcare costs (figure 1) of $£ 1.4$ billion, compared with $£ 4.4$ billion for cancer, £2.4 billion for CHD and £1.8 billion for stroke. However, the costs placed by dementia on the social care system ( $£ 10.2$ billion) outweigh the social care costs of cancer, CHD and stroke combined. Combining the costs to the UK health and social services, dementia was estimated to cost $£ 11.6$ billion in 2012, compared with $£ 5.0$ billion for cancer, £2.9 billion for stroke and £2.5 billion for CHD. Hence, for every $£ 10$ in health and social care costs of each disease, cancer received $£ 1.08$ in research funding, CHD received $£ 0.65$, followed by stroke with $£ 0.19$ and finally dementia with $£ 0.08$ (table 3 ).

Comparing measures of burden of disease with levels of research funding revealed a wide disparity between charity and governmental research spend (table 3). When examining levels of research spend by charities, regardless of the measure of disease burden under investigation, cancer received considerably more research funding than any of the other three diseases. For example, per disease case, total charity funding was $£ 172$ for cancer, compared with £22 for dementia and £11 for stroke. Per DALY lost, charity research funding was $£ 133$ for cancer, £61 for CHD, £42 for dementia and £19 for stroke.

\section{DISCUSSION}

In 2006, an influential government review investigating how public bodies target medical research funding recommended that the impact of diseases on the UK population and economy should be assessed to determine the UK health priorities which would, in turn, inform the nation's health research priorities. Our results highlight that, in contrast to the estimated burden of disease, research funding into stroke is low compared with other diseases. Out of $£ 856$ million made available by charities and government for cancer, CHD, dementia and stroke research in 2012, 64\% was devoted to cancer, $19 \%$ to $\mathrm{CHD}, 11 \%$ to dementia and $7 \%$ to stroke. There was wide variation between charities and governmental organisations in the distribution of research spending across disease areas. Of the $£ 347$ million of governmental research spend on the four conditions under study, $46 \%$ was devoted to cancer, $21 \%$ to $\mathrm{CHD}, 21 \%$ to dementia and $12 \%$ to stroke. This is in

Table 2 Research funding by disease

\begin{tabular}{|c|c|c|c|c|c|c|}
\hline & \multicolumn{3}{|c|}{$\begin{array}{l}\text { Research funding } 2012 \\
£ \text { thousands (\%) }\end{array}$} & \multicolumn{3}{|c|}{$\begin{array}{l}\text { Research funding } 2008 \\
£ \text { thousands }\end{array}$} \\
\hline & Charity & Government & Total & Charity & Government & Total \\
\hline Cancer & $387414(76)$ & $156640(45)$ & $544055(64)$ & $323771(76)$ & $266640(66)$ & $590411(71)$ \\
\hline CHD & $91486(18)$ & $74699(21)$ & 166185 (19) & $85031(20)$ & $84229(21)$ & $169260(20)$ \\
\hline Dementia & 16637 (3) & 73481 (21) & $90118(10)$ & $13913(3)$ & 36331 (9) & 50244 (6) \\
\hline Stroke & $13323(3)$ & 42641 (12) & $55964(7)$ & $5833(1)$ & $17522(4)$ & $23355(3)$ \\
\hline Total & $508859(100)$ & $347462(100)$ & $856321(100)$ & $428548(100)$ & $404723(100)$ & $833270(100)$ \\
\hline
\end{tabular}


Table 3 Research funding and disease burden

\begin{tabular}{|c|c|c|c|c|}
\hline & Cancer & CHD & Dementia & Stroke \\
\hline Total number of cases, thousands & 2254 & 2286 & 761 & 1168 \\
\hline \multicolumn{5}{|l|}{ Funding per case } \\
\hline Government & $£ 69$ & $£ 33$ & $£ 97$ & $£ 37$ \\
\hline Charities & $£ 172$ & $£ 40$ & $£ 22$ & $£ 11$ \\
\hline Total & $£ 241$ & $£ 73$ & $£ 118$ & $£ 48$ \\
\hline Total number of DALYs, thousands & 2914 & 1504 & 400 & 686 \\
\hline \multicolumn{5}{|l|}{ Funding per DALY } \\
\hline Government & $£ 54$ & $£ 50$ & $£ 184$ & $£ 62$ \\
\hline Charities & $£ 133$ & $£ 61$ & $£ 42$ & $£ 19$ \\
\hline Total & $£ 187$ & $£ 110$ & $£ 225$ & $£ 82$ \\
\hline Total health and social care, $£$ millions & $£ 5020$ & $£ 2544$ & $£ 11580$ & $£ 2936$ \\
\hline \multicolumn{5}{|l|}{ Funding per $£ 10$ in disease costs } \\
\hline Government & $£ 0.31$ & $£ 0.29$ & $£ 0.06$ & $£ 0.15$ \\
\hline Charities & $£ 0.77$ & $£ 0.36$ & $£ 0.01$ & $£ 0.05$ \\
\hline Total & $£ 1.08$ & $£ 0.65$ & $£ 0.08$ & $£ 0.19$ \\
\hline
\end{tabular}

stark contrast with the charity sector, where $76 \%$ of the total spend on the four conditions under study was devoted to cancer, $18 \%$ to $\mathrm{CHD}, 3 \%$ to dementia and $3 \%$ to stroke.

This paper updates previous estimates of research expenditure for $2008 .^{9}$ Since then, overall research expenditure by government bodies has increased by around $20 \%$. Despite this, our analysis of total government expenditure on the four diseases under study in 2012 produces a slightly lower figure than in 2008 ( $£ 347$ million vs $£ 405$ million), with the biggest difference being on cancer research expenditure ( $£ 157$ million in 2012 vs $£ 267$ million in 2008). Data supplied from the MRC showed that in 2008 total research funding on cancer was $£ 89$ million. ${ }^{9}$ MRC Annual Reports show a reduction in research programme expenditure on cancer from $8.9 \%$ of the total-or $£ 67 \mathrm{~m}$-in $2009 / 2010$ to $6.2 \%$ of the total-or $£ 48 \mathrm{~m}$-in 2012/2013. ${ }^{20}{ }^{21}$ Equally, for the National Institute for Health Research (NIHR), 2008 research funding on cancer was $£ 159$ million, compared with $£ 88$ million in 2012. However, the methodology used

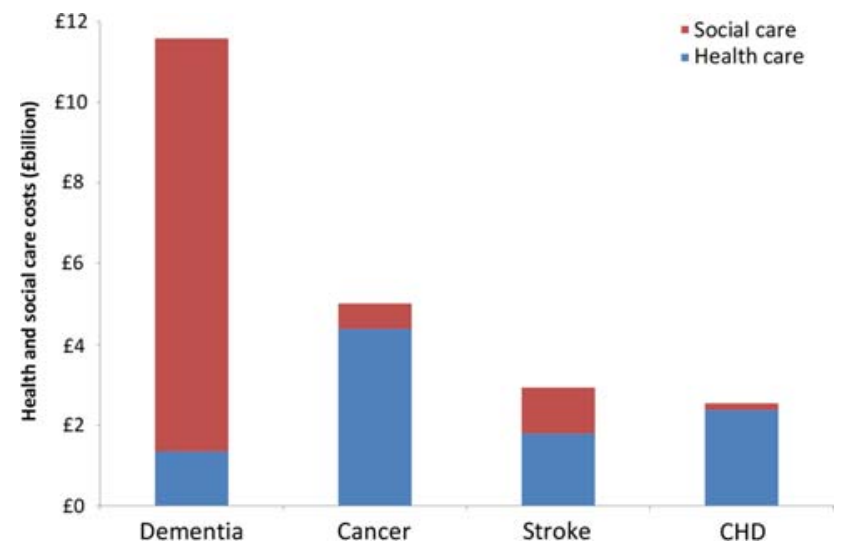

Figure 1 Economic burden of disease (CHD, coronary heart disease). to obtain NIHR research funding for this study was different to that used in 2008. Unlike in 2008, we did not receive a response to our request for information and instead, extracted detailed information for over 350 research grants starting in 2012, with a combined value of $£ 217$ million. In total, £650 million of research infrastructure spending was then attributed to each of the four conditions assuming that the proportion of research infrastructure spending attributable to a specific condition would be the same as the proportion of research grant funding for that same condition. Therefore, some caution should be placed when making comparisons on the absolute levels of research expenditure by disease between 2008 and 2012.

Over the 4-year interval, governmental research expenditure seems to have increased considerably in relative terms for stroke and dementia. In $2008,66 \%$ of total governmental funding into the four conditions under study was devoted to cancer, $21 \%$ to CHD, $9 \%$ to dementia and just $4 \%$ to stroke. In 2012, the proportions devoted to dementia and stroke had increased to $21 \%$ and $12 \%$, respectively, with cancer accounting for $46 \%$ of total research spend. Although a number of reasons could be put forward for this diversification of governmental research funding, the increases in research funding into dementia and stroke could be explained partly by the strong commitment by the UK government, since 2010, to increase the levels of research funding into dementia ${ }^{10}$ and within a context when overall expenditure on research also increased. Stroke, as a recognised major risk factor for developing dementia, ${ }^{22}$ may also have benefited from this commitment.

In contrast to government research funding, the relative proportions of charity research funding into cancer, CHD, dementia and stroke remained virtually unchanged between 2008 and 2012. The high levels of charity research funding into cancer relative to other conditions, such as dementia or stroke, could be explained in part by 
public preferences towards cancer charities. This might reflect heightened fear or dread of particular diseases, perceptions of life-time risk or a form of ageism, with the view that dementia and stroke are inevitable conditions associated with the ageing process. ${ }^{6}$ Additionally, cancer is a very heterogeneous condition, with over 200 types of cancer affecting all major organs, which could explain in part why cancer as a whole receives such a high proportion of research funds.

Our study only quantified the research expenditure into stroke, cancer, CHD and dementia in the UK. However, these four diseases are major conditions in all areas of the world, with other countries also devoting resources to research. Therefore, it is possible that other countries could devote substantial resources to those areas that are relatively underfunded in the UK. However, evidence from Europe showed that the UK accounted for $40 \%$ of all European research expenditure on diseases of the brain, which included both stroke and dementia. ${ }^{23}$ Systematic analysis of research expenditure by condition could enable stronger research collaborations across countries, particularly in those diseases that are underfunded in relative terms and reduce research duplication.

Additional limitations to our study are acknowledged. First, as a result of the very large numbers of registered UK charities, we were unable to extract funding information from all of them. Second, although we took great care to avoid double counting of research funding (eg, charities making grants to each other), this could not always be identified. We omitted industry R\&D on the grounds that it is not directly a subject of public policy and due to the difficulty in obtaining detailed information on research spend by the pharmaceutical industry. Fourth, the economic burden of the four diseases under study was obtained from a previously published study evaluating the cost to the UK health and social care system in $2008,{ }^{9}$ with costs updated to 2012 using healthcare inflation indices. We, therefore, assumed that the only change between 2008 and 2012 was the price of health and social care. Finally, some caution should be placed when comparing the figures on the absolute levels of research expenditure between governmental organisations and charities. In the UK, many governmental funding streams cover indirect research expenditure, such as building maintenance, university administration and library services. ${ }^{24}$ However charities, in general, do not cover such indirect research activities in their grants and only cover direct research expenditure, for example, research staff salaries.

In conclusion, our study shows that there has been much progress by governmental research organisations to increase the levels of funding for dementia and stroke. However, the total overall research funding by charities and government into stroke is small when compared with its burden, and disproportionately low when compared with cancer.

Acknowledgements The authors are grateful to Archie Gray for his assistance in collating data for this study. We would like to acknowledge all of the charities and governmental organisations that very helpfully responded to our requests for information. We thank the Charity Commission for providing us with a comprehensive list of relevant charities.

Contributors RL-F and $\mathrm{JL}$ were responsible for data collection and management, did the analyses and wrote the manuscript. AG supervised the analysis, provided direct input into the interpretation of results and revised, edited and decided on the final content of the manuscript. All authors had full access to all of the data in the study and can take responsibility for the integrity of the data and the accuracy of the data analysis.

Funding This work was funded by the Stroke Association.

Competing interests None.

Provenance and peer review Not commissioned; externally peer reviewed.

Data sharing statement Data on all of the organisation's funding health research into cancer, dementia, coronary heart disease and stroke are included in the manuscript and online only material.

Open Access This is an Open Access article distributed in accordance with the Creative Commons Attribution Non Commercial (CC BY-NC 4.0) license, which permits others to distribute, remix, adapt, build upon this work noncommercially, and license their derivative works on different terms, provided the original work is properly cited and the use is non-commercial. See: http:// creativecommons.org/licenses/by-nc/4.0/

\section{REFERENCES}

1. Murray CJ, Vos T, Lozano R, et al. Disability-adjusted life years (DALYs) for 291 diseases and injuries in 21 regions, 1990-2010: a systematic analysis for the Global Burden of Disease Study 2010. Lancet 2012;380:2197-223.

2. Office for National Statistics. Mortality Statistics: Deaths Registered in England and Wales (Series DR). 2012. http://www.ons.gov.uk/ons/ publications/re-reference-tables.html?edition=tcm\%3A77-325289 (accessed 26 Mar 2014).

3. General Register Office for Scotland. Vital Events Reference Tables 2012. http://www.gro-scotland.gov.uk/statistics/theme/ vital-events/general/ref-tables/2012/section-6-deaths-causes.html (accessed 26 Mar 2014).

4. Northern Ireland Statistics \& Research Agency. Deaths by cause. http://www.nisra.gov.uk/demography/defaultasp14.htm (accessed 26 Mar 2014).

5. Cooksey D. A review of UK health research funding. London: HMSO, 2006.

6. Lowin A, Knapp M, McCrone P. Alzheimer's disease in the UK comparative evidence on cost of illness and volume of health services research funding. Int J Geriatr Psychiatry 2001;16:1143-8.

7. Rothwell PM. The high cost of not funding stroke research: a comparison with heart disease and cancer. Lancet 2001;357:1612-16.

8. Pendlebury ST, Rothwell PM, Algra A, et al. Underfunding of stroke research: a Europe-wide problem. Stroke 2004;35:2368-71.

9. Luengo-Fernandez R, Leal J, Gray AM. UK research expenditure on dementia, heart disease, stroke and cancer: are levels of spending related to disease burden? Eur J Neurol 2012;19:149-54.

10. UK Government. The Coalition: Our Programme for Government https://www.gov.uk/government/publications/the-coalitiondocumentation (accessed 31 Jan 2014).

11. UK Clinical Research Collaboration. UK Health Research Analysis 2009/10. http://www.ukcrc.org/researchcoordination/ healthresearchanalysis/ukanalysis/ (accessed 15 Jan 2014).

12. Hofman A, Rocca WA, Brayne C, et al. The prevalence of dementia in Europe: a collaborative study of 1980-1990 findings. Int J Epidemiol 1991;20:736-48.

13. Matthews FE, Arthur A, Barnes LE, et al. A two-decade comparison of prevalence of dementia in individuals aged 65 years and older from three geographical areas of England: results of the Cognitive Function and Ageing Study I and II. Lancet 2013;382:1405-12.

14. Office for National Statistics. Population Estimates for UK, England and Wales, Scotland and Northern Ireland-Mid 2012. http://www. ons.gov.uk/ons/taxonomy/index.html?nscl=Population+Estimates+by +Age+and+Sex\#tab-data-tables (accessed 7 Jan 2014)

15. Maddams J, Brewster D, Gavin A, et al. Cancer prevalence in the United Kingdom: estimates for 2008. Br J Cancer 2009;101:541-7.

16. UK QOF Database. Data for Stroke 1. http://www.gpcontract.co.uk/ child/UK/STROKE\%201/12 (accessed 24 Jan 2014). 
17. UK QOF Database. Coronary heart disease. http://www.gpcontract. co.uk/browse/UK/Coronary\%20heart\%20disease/12 (accessed 24 Jan 2014).

18. Institute for Health Metrics and Evaluation. Global Burden of Disease Study 2010 (GBD 2010) Data Downloads. http://ghdx. healthmetricsandevaluation.org/global-burden-disease-study-2010gbd-2010-data-downloads (accessed 24 Jan 2014).

19. Curtis L. Unit Costs of Health and Social Care 2013. http://www. pssru.ac.uk/project-pages/unit-costs/2013/ (accessed 24 Jan 2014).

20. Medical Research Council. Annual report and accounts 2009/10. http://www.mrc.ac.uk/Newspublications/Publications/AnnualReport/ index.htm (accessed 3 Feb 2014).
21. Medical Research Council. Annual report and accounts 2012/13. http://www.mrc.ac.uk/Newspublications/Publications/AnnualReport/ index.htm (accessed 3 Feb 2014).

22. Pendlebury ST, Rothwell PM. Prevalence, incidence, and factors associated with pre-stroke and post-stroke dementia: a systematic review and meta-analysis. Lancet Neurol 2009;8:1006-18.

23. Sobocki P, Lekander I, Berwick S, et al. Resource allocation to brain research in Europe (RABRE). Eur $J$ Neurosci 2006;24:2691-3.

24. National Institute for Health Research (NIHR). FAQS-Finance. http://www.nihr.ac.uk/CCF/NIHR\%20Finance\%20Form_FAQs.pdf (accessed 19 Jan 2015). 